\title{
Acetaldehyde Enhances Acquisition of Nicotine Self-Administration in Adolescent Rats
}

\author{
James D Belluzzi*,',3, Ruihua Wang' and Frances M Leslie ${ }^{1,2,3}$ \\ 'Department of Pharmacology, College of Medicine, University of California, Irvine, CA, USA; ${ }^{2}$ Department of Anatomy and Neurobiology, College \\ of Medicine, University of California, Irvine, CA, USA; ${ }^{3}$ Transdisciplinary Tobacco Use Research Center, University of California, Irvine, CA, USA
}

\begin{abstract}
Tobacco use has one of the highest rates of addiction and relapse of any abused drug. Paradoxically, however, in animal models of reinforcement nicotine appears weak compared to other abused drugs. We report here that acetaldehyde, a major component of tobacco smoke, enhances nicotine self-administration. Juvenile and adult male rats were implanted with intravenous catheters and tested for self-administration 4 days later at postnatal day 27 or 90, respectively. Animals were tested, without prior response training, in five daily 3-h sessions where each nose-poke delivered an intravenous injection followed by a 60-s timeout. Animals (I I-13/group) were offered one of the following solutions: nicotine $(30 \mu \mathrm{g} / \mathrm{kg} / \mathrm{injection})$, acetaldehyde $(16 \mu \mathrm{g} / \mathrm{kg} / \mathrm{inj})$, nicotine $(30 \mu \mathrm{g} / \mathrm{kg} / \mathrm{inj})+$ acetaldehyde $(16 \mu g / k g / i n j)$, or saline. The youngest animals responded significantly more for nic + acet than for saline or for either drug alone. Responding at the reinforced hole was significantly higher than at the nonreinforced hole or at the reinforced hole during noncontingent injections of nic + acet. Tests with receptor antagonists indicated that these drug effects are mediated by central, but not peripheral, nicotinic receptors. There was an age-related decline in self-administration of nic + acet, but not for cocaine. Taken together, these results indicate that acetaldehyde, at the low concentrations found in tobacco smoke, interacts with nicotine to increase responding in a stringent self-administration acquisition test where nicotine alone is only weakly reinforcing, and that adolescent animals are more sensitive to these actions than adults. Animal models of tobacco addiction could be improved by combining acetaldehyde, and possibly other smoke components, with nicotine to more accurately reflect the pharmacological profile of tobacco smoke.

Neuropsychopharmacology (2005) 30, 705-7/2, advance online publication, 20 October 2004; doi: | 0.1038/sj.npp. I 300586
\end{abstract}

Keywords: self-administration; nicotine; acetaldehyde; adolescence; reinforcement; tobacco

\section{INTRODUCTION}

Tobacco use has one of the highest rates of addiction of any abused drug (Kandel et al, 1997), with a third to a half of all experimenters becoming addicted smokers (Henningfield et al, 1998). Relapse following unaided quit attempts approaches $97 \%$ (Shiffman et al, 1998). There is now strong evidence that nicotine, the most prevalent pharmacological agent in tobacco smoke, mediates the primary reinforcement that leads to dependence and addiction (Harvey et al, 2004). However, when nicotine is tested in animal models used to demonstrate the reinforcing strength of psychostimulants, such as self-administration or conditioned place preference, it appears to be a relatively weak reinforcer (Stolerman and Jarvis, 1995). In direct comparisons with

\footnotetext{
*Correspondence: Dr JD Belluzzi, Department of Pharmacology, College of Medicine, University of California, Irvine, CA 92697-4625, USA, Tel: + I 949824 547I, Fax: + I 9498244855 ,

E-mail: belluzzi@uci.edu

Received 16 April 2004; revised I September 2004; accepted 6 September 2004

Online publication: I0 September 2004 at http://www.acnp.org/citations/ Npp09| 00404 I78/default.pdf
}

cocaine (Manzardo et al, 2002), we have shown that adult rats chose cocaine over nicotine at all doses tested. This paradoxical situation has led some to claim that nicotine is not addictive (Robinson and Pritchard, 1992), but if the experimental conditions are modified to increase the speed of drug delivery and shorten the test sessions, nicotine is reliably self-administered (Corrigall and Coen, 1989; Donny et al, 1995). Furthermore, evidence is accumulating that nicotine reinforcement is particularly dependent on nonpharmacological stimuli and, when these are present, nicotine supports stable and reliable self-administration (Caggiula et al, 2001, 2002).

There is substantial evidence that abstinent smokers experience withdrawal symptoms (Bergen and Caporaso, 1999), but that the underlying dependence may not be entirely due to nicotine. For example, the nicotinic receptor antagonist mecamylamine precipitates withdrawal symptoms in chronically nicotine-treated rats (Watkins et al, 2000), but not in human smokers (Eissenberg et al, 1996). Furthermore, nicotine delivered by patch is unable to reduce all withdrawal symptoms in human smokers, whereas denicotinized cigarettes do significantly reduce craving and withdrawal (Rose et al, 2000). This apparent 
limitation of nicotine alone in reducing withdrawal symptoms may be due, in part, to the presence of some additional agent or agents that contribute to reinforcement, tolerance, and/or dependence in tobacco smoke.

The important differences between inhaled tobacco smoke and intravenous nicotine have only rarely been mentioned in the literature (Domino, 1998), even though it is well known that cigarette smoke contains thousands of chemicals including compounds that may have pharmacological actions of their own (US Surgeon General's Report, 1989). The most extensively studied smoke constituent, other than nicotine, is acetaldehyde. It is one of the most abundant components of tobacco smoke and may have reinforcing effects when inhaled (Bates et al, 1999). The possible role of acetaldehyde in alcohol addiction has also received considerable attention (Eriksson, 2001). Acetaldehyde, the primary metabolic product of alcohol, has identifiable reinforcing properties (Amit and Smith, 1985), and may be responsible for some withdrawal symptoms following cessation of alcohol intake (Ward et al, 1997). Rats will work to self-administer acetaldehyde (Amit and Smith, 1985), but at doses much higher than those found in tobacco smoke. However, unpublished data, recently made available during settlement of the tobacco company lawsuits, suggest that low concentrations of acetaldehyde may synergistically enhance nicotine's reinforcing effects in selfadministering rats (DeNoble and Mele, 1983).

There is accumulating evidence that adolescence is a period of heightened sensitivity to the effects of nicotine. Adolescence appears to be a critical period for the initiation of smoking in humans (Eissenberg and Balster, 2000), and the acute effects of nicotine enhance rat locomotor activity in early adolescent rats and suppress it at later ages (Vastola et al, 2002; Faraday et al, 2003; Belluzzi et al, 2004). Early adolescence also appears to be a period of increased sensitivity to the rewarding effects of nicotine (Adriani et al, 2002; Vastola et al, 2002; Belluzzi et al, 2004), and Levin and co-workers have shown that female rats, aged P54, have higher rates of nicotine intake than do older animals (Levin et al, 2003). Thus, we have evaluated the possible synergistic interactions of acetaldehyde and nicotine in a rat self-administration acquisition test in both juvenile and adult rats. Our results provide support for the view that nicotine is not the only component of cigarette smoke that contributes to tobacco addiction, and that age is a critical factor in the rewarding effects of tobacco constituents.

\section{MATERIALS AND METHODS}

\section{Animals}

Male Sprague-Dawley rats were obtained at postnatal $(\mathrm{P})$ days 16-19, P30, and P80. Juvenile animals remained with their dam until weaning (P21) when they were housed in groups of four until surgery. After surgery, all animals were single-housed and maintained on a 12-h light/dark cycle (lights on at 0700) with food and water available ad libitum. Rats were allowed at least 3 days of postoperative recovery before any treatments began. All tests were performed during the light part of the light-dark cycle. The animals used in this study were housed in an AAALAC-accredited vivarium maintained by UCI University Laboratory Animal Resources personnel. All experimental procedures were performed in compliance with NIH Guide for Care and Use of Laboratory Animals (NIH No. 85-23, rev. 1985) and approved by the UCI Institutional Animal Care and Use Committee.

\section{Catheter Construction}

Catheter construction has been described previously (Manzardo et al, 2002). The catheter/polyethylene assembly consisted of Silastic tubing $(0.03 \mathrm{~cm} \mathrm{ID} \times 0.064 \mathrm{~cm} \mathrm{OD;}$ $15 \mathrm{~cm}$ for P86, $12 \mathrm{~cm}$ for P22 and P32) attached to a guide cannula (Plastic Products Inc., C313G-5up) that was bent at a right angle. One end of the Silastic tubing was dipped in Hemo-De (Fisher Scientific) for a few minutes until expanded. The Hemo-De was drained and the tubing carefully slid onto the guide cannula. A 2-cm length of large tubing $(0.064 \mathrm{~cm}$ ID $\times 0.119 \mathrm{~cm} \mathrm{OD})$ was expanded in Hemo-De for several minutes, drained, and slid onto a 3$\mathrm{cm}, 19$-gauge stainless cannula $(0.068 \mathrm{~cm} \mathrm{ID} \times 0.107 \mathrm{~cm}$ OD). The cannula/tubing unit was slid over the catheter up to the base and the tubing was slid off the stainless cannula leaving it to protect the catheter at the junction with the cannula. The cannula assembly was washed and flushed with distilled water. The guide cannula was embedded in cranioplastic cement and allowed to dry. A square of Marlex mesh $(2.5 \mathrm{~cm}$ for P86 rats, $2 \mathrm{~cm}$ for P32 and P22 rats) was secured to the bottom of the dry cranioplastic with Silux. The catheter was inserted into the middle of a 1-cm square of Mersiline mesh and glued at $9 \mathrm{~cm}$ (P86), $8 \mathrm{~cm}$ (P32), or $7 \mathrm{~cm}$ (P22) from the end of the catheter. The end of the catheter then was cut to the proper length: $3.25 \mathrm{~cm}$ for P86, $2 \mathrm{~cm}$ for P32, and $1.5 \mathrm{~cm}$ for P22 from the small mesh.

\section{Surgical Implantation of Intravenous Catheters}

Surgery commenced at ages P22-23, P32-33, or P86-87, respectively. Animals were anesthetized with Equithesin $(0.3 \mathrm{ml} / 100 \mathrm{~g}$, i.p. for $\mathrm{P} 86,0.25 \mathrm{ml} / 100 \mathrm{~g}$, i.p. for $\mathrm{P} 22$ and P32) and a chronic catheter was surgically implanted into the right external jugular vein using a method similar to that described by Caine et al (1993). The catheter was passed subcutaneously from the animal's back to the jugular vein where the tubing was inserted. The polyethylene assembly was mounted on the animal's back. The wounds were closed with wound clips, antiseptic ointment was applied to the wounds, and Baytril $(0.1 \mathrm{ml} / 150 \mathrm{~g}$, i.m.) was injected to prevent infection. Antiseptic ointment was applied to the exposed cannula housing after each surgery to prevent infection, and a metal cap was attached to prevent damage to the cannula. The animals were kept in a warm cage for postsurgical observation until they emerged from anesthesia.

The catheters were flushed daily with $0.2 \mathrm{ml}$ sterile heparinized saline solution $(0.6$ or $0.3 \mathrm{ml}$ of $1000 \mathrm{U} / \mathrm{ml}$ heparin in $30 \mathrm{ml}$ saline for P86, or P32 and P22, respectively) to maintain catheter patency. On test days, heparinized saline was injected before and after the selfadministration session. After the final daily flush, the injection tubing was heat-sealed near the top of the cannula and left on in order to maintain a closed system and prevent 
clogging of the catheter in the home cage. The exposed cannula was protected by a threaded aluminum standoff. After the final daily test session, Brevital $(60 \mathrm{mg}$ in $9 \mathrm{ml}$ sterile saline) or Propofol (0.1 ml P27, P37; $0.2 \mathrm{ml}$ P90) was injected through the catheter to test the patency of the IV catheter as indicated by rapid (5-10 s) anesthesia. Data were discarded from all animals not demonstrating rapid anesthesia.

\section{Drug Self-Administration}

At 3-5 days after surgery, rats were tested in selfadministration chambers with two nose-poke holes side by side in the door. A 10-ml syringe was mounted in an infusion pump, located outside the test chamber, and connected by polyethylene tubing to a feed-through swivel located above the test chamber. The other side of the feedthrough swivel was connected to the infusion cannula on the animal's back with polyethylene tubing covered by a steel spring to prevent puncture from biting. The syringe was filled with enough solution to provide a maximum of 100 injections. During each 5.6-s 100- $\mu$ l infusion, a lowintensity $1800-\mathrm{Hz}$ tone sounded and, immediately after the drug infusion, the signal light over the hole went out for $60 \mathrm{~s}$ during which time responses were counted but had no effect. The control of all experimental parameters and the collection of all data were controlled by a multichannel computer system (MED Associates Inc., St Albans, VT).

\section{Acquisition of Nicotine/Acetaldehyde Self-Administration}

Initial acquisition of drug self-administration was measured during two postnatal periods that have previously been defined as early adolescence and adulthood (Spear, 2000): P27-31 and P90-95. Owing to the brief period between weaning (P21) and surgery (P23) in the young animals, there was insufficient time for food deprivation and leverpress training for food reward prior to self-administration testing and all age groups were tested naïve to experimental conditions. In an attempt to mitigate some of the disadvantages of testing naïve animals, a nose-poke response was used. This response relies on the animals' natural olfactory exploration to provide adequate initial levels of responding. Priming at the start of each session was not employed because of possible aversive effects of noncontingent injections in naïve animals.

A total of 76 juveniles and 44 adults were used in the experiment. The difficulty of catheter placement in 55-g rats and their rapid growth led to 16 failed catheters before the end of the experiment; data were excluded from these animals. No catheters failed in the adult animals. Tests for acquisition of self-administration commenced without prior response training and consisted of five daily 3-h sessions with a fixed-ratio one (FR 1) reinforcement schedule. Each nose-poke at the reinforced hole delivered one of the following agents: nicotine $(30 \mu \mathrm{g} / \mathrm{kg} /$ injection $)$, acetaldehyde $(16 \mu \mathrm{g} / \mathrm{kg} / \mathrm{inj}), \quad$ nicotine $(30 \mu \mathrm{g} / \mathrm{kg} / \mathrm{inj})+$ acetaldehyde $(16 \mu \mathrm{g} / \mathrm{kg} / \mathrm{inj})$ or saline vehicle. A nicotine dose of $30 \mu \mathrm{g} /$ $\mathrm{kg} / \mathrm{inj}$ was chosen because it is at the peak of the adult doseresponse curve (Corrigall and Coen, 1989; Watkins et al, 1999), and because we have pilot data in P27 rats that indicate it is also the peak dose in this age group. The stringent procedural requirements necessitated the most reinforcing dose to facilitate responding for nicotine alone. To control for nonspecific activating effects of drugs, nonreinforced nose-pokes at a second adjacent hole were counted, but they had no programmed consequences. An additional control for nonspecific activating effects of the drugs consisted of a group of animals given noncontingent injections of nic + acet. These animals received 25 injections - the approximate mean number of self-injections in the nic + acet group - programmed by computer at equal intervals during the $3-h$ test sessions. All timing and counting of responses for the noncontingent controls were carried out in a manner identical to that for the reinforced animals. Nose-pokes in the reinforced hole initiated the tone for $5.6 \mathrm{~s}$ followed by lights-out for $60 \mathrm{~s}$, but did not deliver an injection or delay any noncontingent computercontrolled injections.

\section{Acetaldehyde Dose-Response in Nicotine/Acetaldehyde Self-Administration}

Three additional groups of P27 animals ( $n=6-7 /$ group) were tested for acquisition of nic + acet self-administration using the same test parameters described in Experiment 1. Three doses of acetaldehyde (8-, 16-, and $32 \mu \mathrm{l} / \mathrm{kg} /$ injection) were combined separately with nicotine $(30 \mu \mathrm{l} / \mathrm{kg} / \mathrm{inj})$.

\section{Antagonism of Nicotinic Receptors}

Nicotinic receptor antagonists were tested in a group of eight juvenile animals. These animals were surgically prepared and tested at $\mathrm{P} 30$ for nic + acet self-administration on an FR 1 schedule in a manner identical to the previous experiment. When stable baseline responding ( $\pm 20 \%$ for 2 consecutive days) was achieved, usually within three to four sessions, the animals received a subcutaneous injection of either mecamylamine ( $1 \mathrm{mg} / \mathrm{kg})$, hexamethonium $(5 \mathrm{mg} / \mathrm{kg})$, or saline $15 \mathrm{~min}$ before the daily nic + acet self-administration session. Mecamylamine, which crosses the blood-brain barrier, was tested at a dose that has previously been reported to be effective in reducing nicotine self-administration (Corrigall and Coen, 1989; Watkins et al, 1999). Hexamethonium, which does not cross the blood-brain barrier, was tested at a dose that was higher than the highest ineffective dose $(3 \mathrm{mg} / \mathrm{kg} / \mathrm{s.c}$.) previously reported (Corrigall and Coen, 1989). Treatments were administered in a counterbalanced order separated by at least $72 \mathrm{~h}$ during which stable baselines were restored. All tests were completed between ages P34 and P48. Data were discarded from two animals with unstable baselines and two animals with failed catheters.

\section{Acquisition of Cocaine Self-Administration}

Cocaine was used as a methodological control to test the reliability of the novel self-administration procedure and to evaluate whether early adolescence was a period of enhanced sensitivity to another category of drug reward. For this test, animals at three ages (P27, P37, and P90; $n=9-13$ /age) were surgically implanted with jugular catheters and tested without response training for acquisi- 
tion of cocaine self-administration with the same method used previously for nicotine + acetaldehyde. The absence of any reports about cocaine self-administration in adolescent rats complicated the selection of a cocaine dose. We provided the adolescent rats with $250 \mu \mathrm{g} / \mathrm{kg} / \mathrm{inj}$ during the first 2 days of the FR 1 acquisition period and $750 \mu \mathrm{g} / \mathrm{kg} / \mathrm{inj}$ for the final 3 days. Both doses are in a range that has been shown to produce very reliable self-administration in adults (Caine et al, 2004). For comparison purposes, one additional group $(n=11)$ of P37 animals was tested for acquisition of nicotine + acetaldehyde.

\section{Statistical Analysis of the Data}

For group differences over days (Figure 1), daily total 3-h self-injections for each group over the 5-day acquisition period were analyzed by two-way ANOVA for Treatment $\times$ Day with repeated measures on Day. The significant main or interaction effects were further analyzed by one-way ANOVA for Treatment for each day with Bonferroni- or Dunnett's-adjusted post hoc comparisons. For effects of acetaldehyde dose (Figure 2), 5-day total self-injections for each group were analyzed by one-way ANOVA with Bonferroni-adjusted post hoc comparisons. Daily reinforced and nonreinforced scores were analyzed with a three-way ANOVA on Dose $\times$ Reinforced/Nonreinforced responses $\times$ Day with repeated measures on Day. Antagonist data (Figure 3) were computed as the percentage of baseline because absolute baselines varied among and between animals. The percentage scores were analyzed with a oneway ANOVA with repeated measures on drug and Bonferroni-corrected post hoc comparisons. Age-related changes in mean 5-day total responses (Figure 4) were analyzed with a three-way ANOVA for Age $\times$ Reinforce/ Nonreinforced $\times$ Drug. Significant main or interaction effects were further analyzed with a two-way ANOVA for each drug separately for Age $\times$ Reinforced/Nonreinforced responding with Bonferroni- or Dunnett's-adjusted post hoc comparisons.

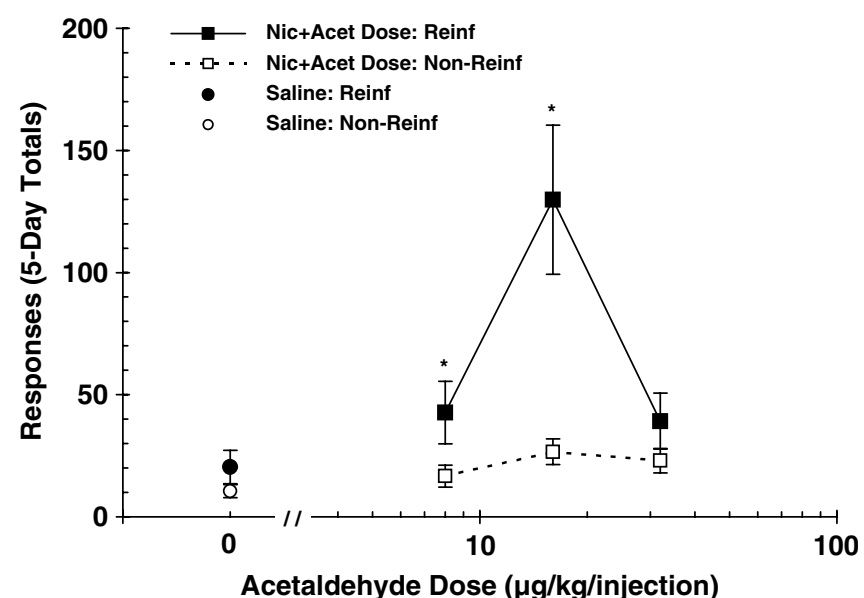

Figure 2 Dose-dependent self-administration of nicotine + acetaldehyde doses. Early adolescent (P27-3I) animals were offered nicotine ( $30 \mu \mathrm{g} / \mathrm{kg} / \mathrm{inj})+$ acetaldehyde $(8,16$, or $32 \mu \mathrm{g} / \mathrm{kg} / \mathrm{inj})$ on an FR I schedule during five daily 3 -h sessions. The 5 -day total self-administration rate for the nicotine $(30 \mu \mathrm{g})+$ acetaldehyde $16-\mu \mathrm{g}$ dose combination was significantly higher than the two other doses or saline $(P \leqslant 0.05) ; n=6-7 /$ group. Saline group from Figure Ia is shown for comparison. $* P \leqslant 0.02$ vs nonreinforced responses.
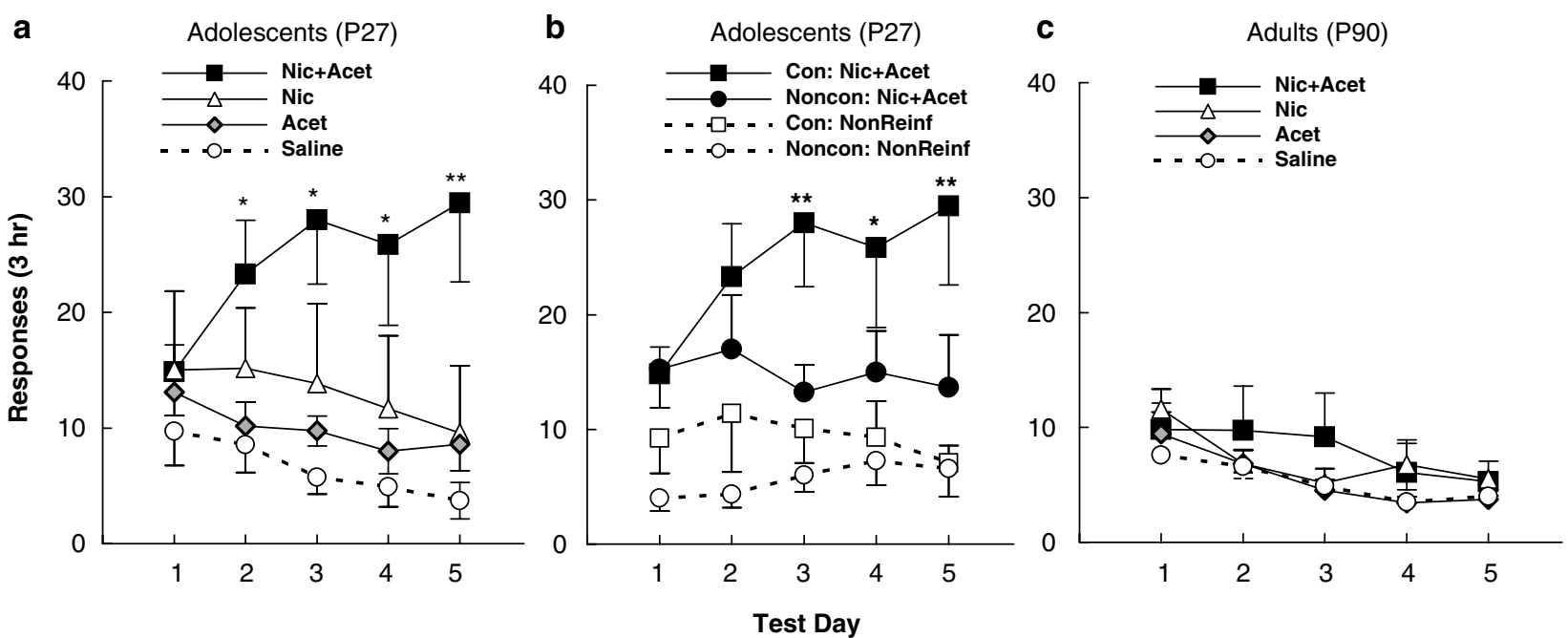

Figure I Effect of acetaldehyde on nicotine self-administration. Naïve animals were tested in daily 3-h self-administration sessions on an FR I schedule. The mean $( \pm S E M)$ total responses are plotted daily for each treatment group. (a) Adolescent (P27-3I) rats self-injected significantly more nicotine $30 \mu g+$ acetaldehyde $16 \mu \mathrm{g}$ (nic + acet) mixture than either nicotine (nic) or acetaldehyde (acet) alone. $* P<0.05$ vs saline; $* * P<0.02$ vs other three groups; $n=1$ II3/group. (b) Effect of nic + acet mixture on nonreinforced and injected responding in early adolescent rats. The group from Figure Ia that self-administered nic + acet (Con: nic + acet) is included for comparison. The Con: NonReinf line shows nose-pokes at the nonreinforced hole for the animals selfadministering nic + acet. Control animals receiving noncontingent injections (Noncon: nic + acet) received 25 programmed injections of nicotine (30 $\mu \mathrm{g})+$ acetaldehyde $(16 \mu \mathrm{g})$ solution during daily 3 -h sessions. This number of injections was approximately the mean daily self-injection total for animals selfadministering the nic + acet mixture. The final group (Noncon: NonReinf) showed responding at the nonreinforced hole during noncontingent injections of $\mathrm{nic}+$ acet. Reinforced responding for the nic + acet mixture was significantly greater than responding under any control condition. $* P<0.05$ vs Con: NonReinf and Noncon: NonReinf groups; ** $P<0.05$ vs the other three groups; $n=1$ I-I3/group. (c) When identical drug solutions were offered to groups of adult (P90-95) rats, there was no significant self-administration of any agent, alone, or in combination; $n=10-12 /$ group. 


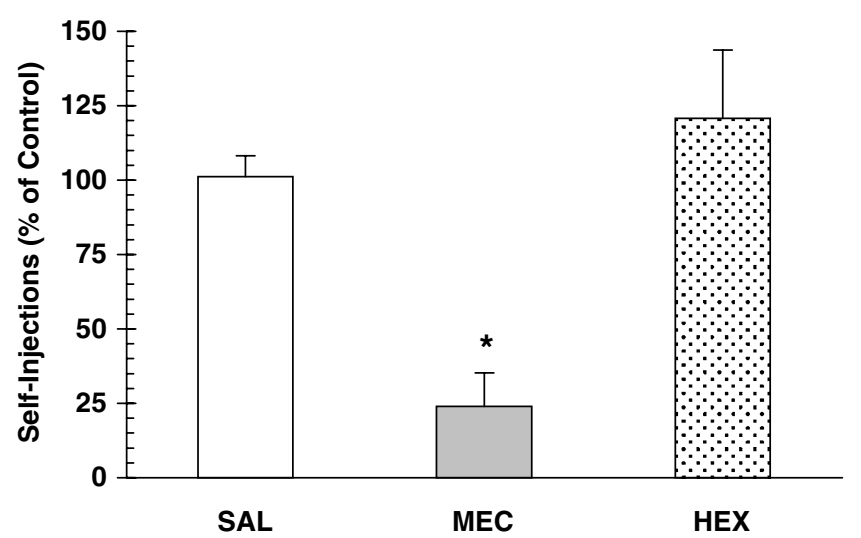

Figure 3 Effects of nicotine receptor antagonists on nic + acet selfadministration. Animals received a subcutaneous injection of saline $1 \mathrm{ml} / \mathrm{kg}$, s.c. (Sal), mecamylamine I mg/kg, s.c. (Mec), or hexamethonium $5 \mathrm{mg} / \mathrm{kg}$, s.c. (Hex) $15 \mathrm{~min}$ before the daily nic + acet self-administration session. $* P<0.05$ vs Sal or Hex; $n=4$

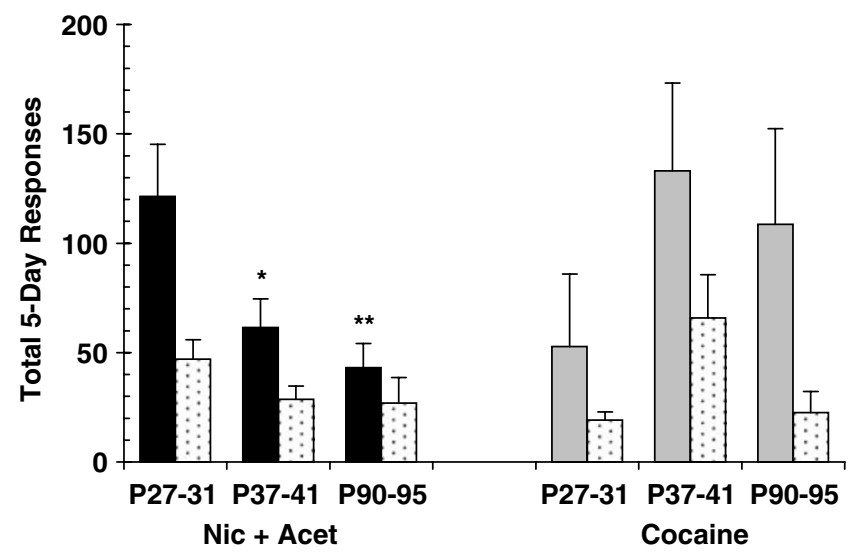

Figure 4 Age-related change in self-administration of nicotine + acetaldehyde or cocaine. Data are shown for 5-day total reinforced and nonreinforced responses for each group; $n=9-13 /$ group. Solid bars indicate reinforced responses and stippled bars indicate nonreinforced responses. ${ }^{*} P<0.05$ vs $\mathrm{P} 31$; $* * * 0.01$.

\section{Drugs}

Nicotine ((-) nicotine ditartrate), mecamylamine hydrochloride, and hexamethonium chloride were purchased from Sigma-Aldrich. Nicotine doses are reported as free base. Cocaine $\mathrm{HCl}$ was obtained from $\mathrm{NIH}$. Acetaldehyde was purchased from Supelco in 1-ml sealed vials in a concentration of $1 \mathrm{mg} / \mathrm{ml}$ of saline. The $16-\mu \mathrm{g}$ acetaldehyde dose was selected based on concentrations ( $\mu \mathrm{g} /$ cigarette) found in mainstream smoke during Standard ISO tests (Bates et al, 1999). The ratio of acetaldehyde $(825 \mu \mathrm{g})$ to nicotine $(1490 \mu \mathrm{g})$ in smoke was 0.554 . The nicotine selfadministration dose, $30 \mu \mathrm{g} / \mathrm{kg} / \mathrm{inj}$, was multiplied by this ratio to yield $16 \mu \mathrm{g} / \mathrm{kg} / \mathrm{inj}$ for the acetaldehyde dose. While acetaldehyde and nicotine content will vary among the many cigarettes available, the ratio of nicotine to acetaldehyde is relatively constant at about 2 to 1 (Hoffmann and Hoffmann, 2001).

\section{RESULTS}

\section{Acquisition of Nicotine/Acetaldehyde}

\section{Self-Administration}

Juvenile animals (P27-P31) quickly learned to self-administer the mixture of nicotine + acetaldehyde (Figure 1a), and displayed sustained self-administration throughout the 5day test period at rates substantially higher than those for nicotine or acetaldehyde alone $\left(\mathrm{F}_{3,44}=3.5990, P=0.0207\right)$. There also was a significant Day $\times$ Treatment interaction $\left(\mathrm{F}_{12,176}=3.5306, P=0.0001\right)$. In control tests (Figure $\left.1 \mathrm{~b}\right)$, there was a significant treatment effect $\left(\mathrm{F}_{3,46}=6.2631\right.$, $P=0.0012$ ) indicating that rats worked for contingent injections of the nic + acet mixture at significantly higher rates than those in the other groups. Analysis across all five daily sessions showed a significant difference between reinforced and nonreinforced responding $\left(\mathrm{F}_{1,23}=25.6978, P<0.0001\right)$ as well as a significant Day $\times$ Treatment $\times$ Reinforcement interaction $\left(\mathrm{F}_{4,92}=3.5598, P=0.0096\right)$. When adult animals (P90-95) were tested in identical experiments (Figure 1c), they did not self-administer the nic + acet mixture or either agent alone at levels significantly higher than saline $\left(\mathrm{F}_{3,40}=0.6984\right.$, $P=0.5586)$

\section{Acetaldehyde Dose-Response in Nicotine/Acetaldehyde Self-Administration}

When three different nic + acet dose ratios were offered to other groups of animals, nic $30 \mu \mathrm{g} /$ acet $16 \mu \mathrm{g}$ supported the highest self-administration rates (Figure 2). Analysis of 5day total responses yielded a significant effect of dose $\left(\mathrm{F}_{3,22}=7.2482, P=0.0015\right)$ and post hoc Bonferroni-adjusted $t$-tests showed the nic $30 \mu \mathrm{g} / \mathrm{acet} 16 \mu \mathrm{g}$ dose significantly higher than the other three groups $(P \leqslant 0.02)$. Analysis of reinforced and nonreinforced responses across all five daily sessions (data not shown) found reinforced responding significantly higher than non-reinforced responding $\left(\mathrm{F}_{1,22}=19.6980, P=0.0002\right)$, a significant Reinforcement $\times$ Dose interaction $\left(\mathrm{F}_{3,22}=6.5615, P=0.0025\right)$, a significant Day $\times$ Dose interaction $\left(\mathrm{F}_{12,88}=2.0208, P=0.0314\right)$, and a significant Reinforcement $\times$ Dose $\times$ Day interaction $\left(\mathrm{F}_{12,88}=2.9099, P=0.0020\right)$.

\section{Antagonism of Nicotinic Receptors}

Tests of the effects of nicotinic receptor antagonists on selfadministration of nic + acet (Figure 3 ) showed a significant effect of drug $\left(\mathrm{F}_{2,6}=8.8772, P=0.0161\right)$. Whereas blockade of both peripheral and central nicotinic receptors by mecamylamine significantly reduced self-administration, selective blockade of peripheral nicotinic receptors by hexamethonium did not.

\section{Comparison with Cocaine Self-Administration}

Comparison of animals of three different ages self-administering either the nic + acet mixture or cocaine showed a significant Age $\times$ Drug interaction $\left(\mathrm{F}_{2,62}=3.6827\right.$, $P=0.0308$ ) for 5-day total responses (Figure 4). Analysis of the groups self-administering nic + acet showed a significant effect of age $\left(F_{2,34}=4.0631, P=0.0262\right)$, with highest responding in the youngest age group. Reinforced 
responding was significantly reduced in the older adolescents and adults. Reinforced and nonreinforced responding were significantly different across age $\left(\mathrm{F}_{1,34}=27.2344\right.$, $P<0.0001)$. Animals self-administering cocaine appeared to have an opposite age-response relationship for reinforced responding, but the differences were not statistically significant $\left(\mathrm{F}_{2,28}=0.9870, P=0.3853\right)$. There was, however, a significant difference between reinforced and nonreinforced responding $\left(\mathrm{F}_{1,28}=11.9319, P=0.0018\right)$.

\section{DISCUSSION}

Our results show that acetaldehyde, a major constituent of tobacco smoke, enhances acquisition of nicotine selfadministration. This enhancement appears synergistic, but the absence of a full dose-response for nicotine precludes a definitive demonstration of synergism. This acetaldehydeinduced enhancement was seen only in adolescent rats and not in adults tested under the same conditions. The agerelated differences in the reinforcing actions of nic + acet are consistent with an emerging literature that suggests adolescents and adults exhibit differential sensitivity to tobacco products. In humans, most adult smokers initiate smoking during adolescence (Eissenberg and Balster, 2000). Adolescents may develop symptoms of dependence after brief tobacco exposure (Kandel and Chen, 2000), and there is evidence that a single withdrawal symptom strongly predicts continued use (DiFranza et al, 2002). In animals, nicotine treatment during adolescence induces long-lasting biochemical, anatomical, physiological, and behavioral changes that are different from changes in adults (Slotkin, 2002; Adriani et al, 2003). Our present findings add to recent studies in both rats (Vastola et al, 2002; Levin et al, 2003; Belluzzi et al, 2004) and mice (Adriani et al, 2002) that have suggested that adolescent rodents may exhibit increased sensitivity to the rewarding effects of nicotine.

\section{Technical Considerations}

Although a number of investigators have used conditioned place preference to evaluate the rewarding efficacy of nicotine and other abused drugs during early adolescence (reviewed by Leslie et al, 2004), this is the first demonstration of intravenous drug self-administration in this age group. Use of young animals that are undergoing rapid growth presented technical challenges that required modification of the experimental conditions that have been used previously for nicotine self-administration. In an earlier study, where animals were required to choose between cocaine and nicotine, we have reported reliable nicotine self-administration in adult rats (Manzardo et al, 2002) using the same parameters for drug delivery, session length, light cycle, and single-housing conditions that were used in the present study and that are commonly used for cocaine self-administration. However, those animals were food deprived and trained to lever-press for food reward prior to self-administration testing in order to facilitate acquisition of the self-administration response. The animals also were fed immediately after the daily self-administration session and kept on a restricted diet throughout the experiment to maintain constant body weight, a procedure that likely enhanced the animals' motivation and facilitated acquisition.

Tests on adolescent rats, which remain in the adolescent developmental phase for less than 3 weeks after weaning (P27-P42), foreclosed the opportunity to subject them to food deprivation, response training, catheter implantation, recovery, and self-administration testing during this short period. Furthermore, there is evidence that food deprivation soon after weaning induces weight loss in adolescent rats that can restrict growth and delay puberty (Delemarre-van de Waal et al, 2002), which might cause abnormal performance in the self-administration tests. Priming injections at the start of each session were also eliminated because such injections might induce aversion in naïve animals. As a result of these technical modifications, adult animals in the present experiment did not self-administer nicotine alone at rates reported previously in self-administration studies (Corrigall and Coen, 1989; Donny et al, 1999). The difficulty of the modified self-administration procedure was confirmed by the low percentage of animals that learned to self-administer cocaine, even though we have reported robust cocaine self-administration using our standard procedure (Manzardo et al, 2001). The fact that nicotine and cocaine alone were not sufficiently rewarding to maintain high levels of responding during acquisition on this difficult behavioral test further underscores the strong motivational influence of the nic + acet mixture in the youngest age group. Further experiments with less stringent testing conditions that permit nicotine self-administration will be required to determine whether some degree of synergism may also occur in adults, as has been suggested previously (DeNoble and Mele, 1983).

\section{Mechanistic Considerations}

Our present findings indicate that nic + acet mixtures are highly reinforcing during early adolescence, with a substantial decline in reward value occurring during later adolescence and in adulthood. These findings are consistent with our recent demonstration of single-trial conditioning by nicotine in an unbiased conditioned place preference test at P28, but not at P38 or P90 (Belluzzi et al, 2004). Such data add to a growing body of evidence from both animal (Vastola et al, 2002; Adriani et al, 2003) and human (O'Loughlin et al, 2003) studies, which indicate unique effects of nicotine during early adolescence. This developmental period does not represent a peak of vulnerability to all drugs of abuse, however. When adolescent and adult animals were compared for their response to cocaine in the present experimental paradigm, age-related trends opposite to those found for nic + acet were obtained. These results are consistent with earlier reports of reduced sensitivity to stimulants during early adolescence (Spear, 2000), and suggest that brain mechanisms for nic + acet and cocaine reinforcement do not completely overlap.

Further studies will be needed to evaluate the mechanisms underlying the apparently synergistic interactions of nicotine and acetaldehyde observed in adolescents. Acetaldehyde is a highly reactive compound that has been shown to react with biological amines to produce novel compounds, such as salsolinol, that have substantial 
biological activity (Jamal et al, 2003). Although it has been suggested that acetaldehyde does not readily cross the blood-brain barrier (Seeman et al, 2002), in the absence of studies of CNS penetration during early adolescence, it is premature to conclude that acetaldehyde does not enter the brain of juvenile animals. Substantial penetration of acetaldehyde into adult brain has been observed following a single intraperitoneal (Heap et al, 1995) or intravenous (Foddai et al, 2004) injection, but at doses considerably higher than those used here. Acetaldehyde has also been shown to display rewarding effects when injected either peripherally (Quintanilla and Tampier, 2003a) or directly into the posterior ventral tegmental area (Rodd-Henricks et al, 2002), but again at doses higher than those used here. Interestingly, studies in rats with differential preference to alcohol have shown that acetaldehyde can produce either place preference or aversion, depending on the activity of aldehyde dehydrogenase 2 within the brain (Quintanilla and Tampier, 2003b).

Our present data suggest that nicotine combined with low doses of acetaldehyde is highly reinforcing to juvenile rats, whereas higher doses may be aversive. The results of our antagonist experiment, in which drug self-administration is blocked by mecamylamine, which penetrates the CNS but not by hexamethonium, which does not, indicate that nic + acet induces reinforcement by activation of central nicotinic receptors. Thus, further study of acetaldehyde in adolescent rats will be needed to determine whether the enhancement of nicotine self-administration results from direct actions on the brain. Other possible mechanisms of interaction that should be considered include acetaldehyde-induced changes in nicotine pharmacokinetics and nicotine-induced enhancement of acetaldehyde as a secondary reinforcer or discriminatory cue (Donny et al, 2003). However, regardless of the mechanism or mechanisms involved, any change in responsiveness to these substances may represent an important factor in the increased vulnerability of human adolescents to tobacco products.

The apparent synergism in the initial reinforcing effects of nicotine and acetaldehyde shown here may be a critical factor in the initiation of smoking. Acetaldehyde may also enhance other effects of nicotine, such as tolerance, withdrawal, cue conditioning, or negative reinforcement. Other major constituents of tobacco smoke, such as pyridine or acetone, may have similar synergistic or additive actions that could combine to increase further the addictive potency of cigarettes. A recent report suggests that MAO inhibitors enhance nicotine's actions (Villegier et al, 2003) and cigarette smoke has been shown to elevate MAO inhibitors in blood (Rommelspacher et al, 2002). If any of these interactions are proven, current animal models of tobacco abuse, relying solely on nicotine, may underestimate the addictive actions of cigarettes and lead to partial or inaccurate conclusions regarding the biochemical, anatomical, and/or behavioral mechanisms that mediate the powerful control that tobacco exerts over human behavior. Animal models that more fully reflect the pharmacological profile of tobacco smoke should help to resolve the debate over nicotine's addictive potency and accelerate the development of more effective therapeutic interventions to reduce the incidence of smoking.

\section{ACKNOWLEDGEMENTS}

This work was supported by NIH Grant DA13332. Portions of this work were presented at the annual meeting of the Society for Research on Nicotine and Tobacco, February 21, 2003, New Orleans, LA and at the New York Academy of Sciences Conference on Adolescent Brain Development, September 19, 2003, New York, NY. We would like to thank Dr Ann Manzardo for her help in starting this project, Shahrdad Lotfipour, Melissa Reyes, Oniel Young, and Ryan Franke for their help during the project, and Dr Bill Farone and Dr Sandra Loughlin for their valuable advice.

\section{REFERENCES}

Adriani W, Macri S, Pacifici R, Laviola G (2002). Peculiar vulnerability to nicotine oral self-administration in mice during early adolescence. Neuropsychopharmacology 27: 212-224.

Adriani W, Spijker S, Deroche-Gamonet V, Laviola G, Le Moal M, Smit $\mathrm{AB}$ et al (2003). Evidence for enhanced neurobehavioral vulnerability to nicotine during periadolescence in rats. J Neurosci 23: 4712-4716.

Amit Z, Smith BR (1985). A multi-dimensional examination of the positive reinforcing properties of acetaldehyde. Alcohol 2: 367-370.

Bates C, McNeill A, Jarvis M, Gray N (1999). The future of tobacco product regulation and labelling in Europe: implications for the forthcoming European Union directive. Tob Control 8: 225-235.

Belluzzi JD, Lee AG, Oliff HS, Leslie FM (2004). Age-dependent effects of nicotine on locomotor activity and conditioned place preference in rats. Psychopharmacology (Berl) 174: 389-395.

Bergen AW, Caporaso N (1999). Cigarette smoking. J Natl Cancer Inst 91: 1365-1375.

Caggiula AR, Donny EC, Chaudhri N, Perkins KA, Evans-Martin FF, Sved AF (2002). Importance of nonpharmacological factors in nicotine self-administration. Physiol Behav 77: 683-687.

Caggiula AR, Donny EC, White AR, Chaudhri N, Booth S, Gharib MA et al (2001). Cue dependency of nicotine self-administration and smoking. Pharmacol Biochem Behav 70: 515-530.

Caine SB, Bowen CA, Yu G, Zuzga D, Negus SS, Mello NK (2004). Effect of gonadectomy and gonadal hormone replacement on cocaine self-administration in female and male rats. Neuropsychopharmacology 29: 929-942.

Caine SB, Lintz R, Koob GF (1993). Intravenous drug selfadministration techniques in animals. In: Sahagal A (ed). Behavioural Neuroscience, Volume II: A Practical Approach. Oxford University Press: Oxford.

Corrigall WA, Coen KM (1989). Nicotine maintains robust selfadministration in rats on a limited-access schedule. Psychopharmacology 99: 473-478.

Delemarre-van de Waal HA, van Coeverden SC, Engelbregt MT (2002). Factors affecting onset of puberty. Horm Res 57(Suppl 2): 15-18.

DeNoble VJ, Mele PC (1983). Behavioral pharmacology annual report. Philip Morris Tobacco Resolution, Bates Number 20605661 http://www.pmdocs.com/getallimg.asp?if = avpidx\& DOCID $=1003060364 / 0441$

DiFranza JR, Savageau JA, Rigotti NA, Fletcher K, Ockene JK, McNeill AD et al (2002). Development of symptoms of tobacco dependence in youths: 30 month follow up data from the DANDY study. Tob Control 11: 228-235.

Domino EF (1998). Tobacco smoking and nicotine neuropsychopharmacology: some future research directions. Neuropsychopharmacology 18: 456-468.

Donny EC, Caggiula AR, Knopf S, Brown C (1995). Nicotine selfadministration in rats. Psychopharmacology (Berl) 122: 390-394. 
Donny EC, Caggiula AR, Mielke MM, Booth S, Gharib MA, Hoffman A et al (1999). Nicotine self-administration in rats on a progressive ratio schedule of reinforcement. Psychopharmacology (Berl) 147: 135-142.

Donny EC, Chaudhri N, Caggiula AR, Evans-Martin FF, Booth S, Gharib MA et al (2003). Operant responding for a visual reinforcer in rats is enhanced by noncontingent nicotine: implications for nicotine self-administration and reinforcement. Psychopharmacology (Berl) 169: 68-76.

Eissenberg T, Balster RL (2000). Initial tobacco use episodes in children and adolescents: current knowledge, future directions. Drug Alcohol Depend 59(Suppl 1): S41-60.

Eissenberg T, Griffiths RR, Stitzer ML (1996). Mecamylamine does not precipitate withdrawal in cigarette smokers. Psychopharmacology (Berl) 127: 328-336.

Eriksson CJ (2001). The role of acetaldehyde in the actions of alcohol (update 2000). Alcohol Clin Exp Res 25: 15S-32S.

Faraday MM, Elliott BM, Phillips JM, Grunberg NE (2003). Adolescent and adult male rats differ in sensitivity to nicotine's activity effects. Pharmacol Biochem Behav 74: 917-931.

Foddai M, Dosia G, Spiga S, Diana M (2004). Acetaldehyde increases dopaminergic neuronal activity in the VTA. Neuropsychopharmacology 29: 530-536.

Harvey DM, Yasar S, Heishman SJ, Panlilio LV, Henningfield JE, Goldberg SR (2004). Nicotine serves as an effective reinforcer of intravenous drug-taking behavior in human cigarette smokers. Psychopharmacology (Berl) 50: 263-270.

Heap L, Ward RJ, Abiaka C, Dexter D, Lawlor M, Pratt O et al (1995). The influence of brain acetaldehyde on oxidative status, dopamine metabolism and visual discrimination task. Biochem Pharmacol 50: 263-270.

Henningfield JE, Benowitz NL, Slade J, Houston TP, Davis RM, Deitchman SD (1998). Reducing the addictiveness of cigarettes. Council on Scientific Affairs, American Medical Association. Tob Control 7: 281-293.

Hoffmann D, Hoffmann I (2001). The changing cigarette: chemical studies and bioassays. In: Shopland DR (ed). Risks Associated with Smoking Cigarettes with Low Machine-Measured Yields of Tar and Nicotine. National Cancer Institute Smoking and Tobacco Control Monograph 13: Washington, DC.

Jamal M, Ameno K, Ameno S, Okada N, Ijiri I (2003). In vivo study of salsolinol produced by a high concentration of acetaldehyde in the striatum and nucleus accumbens of free moving rats. Alcohol Clin Exp Res 27: 79S-84S.

Kandel DB, Chen K (2000). Extent of smoking and nicotine dependence in the United States: 1991-1993. Nicotine Tob Res 2 263-274.

Kandel D, Chen K, Warner LA, Kessler RC, Grant B (1997). Prevalence and demographic correlates of symptoms of last year dependence on alcohol, nicotine, marijuana and cocaine in the US population. Drug Alcohol Depend 44: 11-29.

Leslie FM, Loughlin SE, Wang R, Perez L, Lotfipour S, Belluzzi JD (2004). Adolescent development of forebrain stimulant responsiveness: insights from animal studies. Ann NY Acad Sci 1021: 148-159.

Levin ED, Rezvani AH, Montoya D, Rose JE, Swartzwelder HS (2003). Adolescent-onset nicotine self-administration modeled in female rats. Psychopharmacology (Berl) 169: 141-149.

Manzardo AM, Del Rio JA, Stein L, Belluzzi JD (2001). Rats choose cocaine over dopamine agonists in a two-lever self-administration preference test. Pharmacol Biochem Behav 70: 257-265.
Manzardo AM, Stein L, Belluzzi JD (2002). Rats prefer cocaine over nicotine in a two-lever self-administration choice test. Brain Res 924: $10-19$.

O'Loughlin J, DiFranza J, Tyndale RF, Meshefedjian G, McMillanDavey E, Clarke PB et al (2003). Nicotine-dependence symptoms are associated with smoking frequency in adolescents. Am J Prev Med 25: 219-225.

Quintanilla ME, Tampier L (2003a). Acetaldehyde-reinforcing effects: differences in low-alcohol-drinking (UChA) and highalcohol-drinking (UChB) rats. Alcohol 31: 63-69.

Quintanilla ME, Tampier L (2003b). Brain mitochondrial aldehyde dehydrogenase: relation to acetaldehyde aversion in low-alcoholdrinking (UChA) and high-alcohol-drinking (UChB) rats. Addict Biol 8: 387-397.

Robinson JH, Pritchard WS (1992). The role of nicotine in tobacco use. Psychopharmacology (Berl) 108: 397-407.

Rodd-Henricks ZA, Melendez RI, Zaffaroni A, Goldstein A, McBride WJ, Li TK (2002). The reinforcing effects of acetaldehyde in the posterior ventral tegmental area of alcoholpreferring rats. Pharmacol Biochem Behav 72: 55-64.

Rommelspacher H, Meier-Henco M, Smolka M, Kloft C (2002). The levels of norharman are high enough after smoking to affect monoamineoxidase B in platelets. Eur J Pharmacol 441: 115-125.

Rose JE, Behm FM, Westman EC, Johnson M (2000). Dissociating nicotine and nonnicotine components of cigarette smoking. Pharmacol Biochem Behav 67: 71-81.

Seeman JI, Dixon M, Haussmann HJ (2002). Acetaldehyde in mainstream tobacco smoke: formation and occurrence in smoke and bioavailability in the smoker. Chem Res Toxicol 15: $1331-1350$.

Shiffman S, Mason KM, Henningfield JE (1998). Tobacco dependence treatments: review and prospectus. Annu Rev Public Health 19: 335-358.

Slotkin TA (2002). Nicotine and the adolescent brain: insights from an animal model. Neurotoxicol Teratol 24: 369-384.

Spear LP (2000). The adolescent brain and age-related behavioral manifestations. Neurosci Biobehav Rev 24: 417-463.

Stolerman IP, Jarvis MJ (1995). The scientific case that nicotine is addictive. Psychopharmacology (Berl) 117: 2-10 discussion $14-20$.

US Surgeon General's Report (1989). Reducing the Health Consequences of Smoking, Chapter 2, pp 79-92. http://www.cdc. gov/tobacco/sgr/sgr_1989/.

Vastola BJ, Douglas LA, Varlinskaya EI, Spear LP (2002). Nicotineinduced conditioned place preference in adolescent and adult rats. Physiol Behav 77: 107-114.

Villegier AS, Blanc G, Glowinski J, Tassin JP (2003). Transient behavioral sensitization to nicotine becomes long-lasting with monoamine oxidases inhibitors. Pharmacol Biochem Behav 76: 267-274.

Ward RJ, Colantuoni C, Dahchour A, Quertemont E, De Witte P (1997). Acetaldehyde-induced changes in monoamine and amino acid extracellular microdialysate content of the nucleus accumbens. Neuropharmacology 36: 225-232.

Watkins SS, Epping-Jordan MP, Koob GF, Markou A (1999). Blockade of nicotine self-administration with nicotinic antagonists in rats. Pharmacol Biochem Behav 62: 743-751.

Watkins SS, Stinus L, Koob GF, Markou A (2000). Reward and somatic changes during precipitated nicotine withdrawal in rats: centrally and peripherally mediated effects. J Pharmacol Exp Ther 292: 1053-1064. 